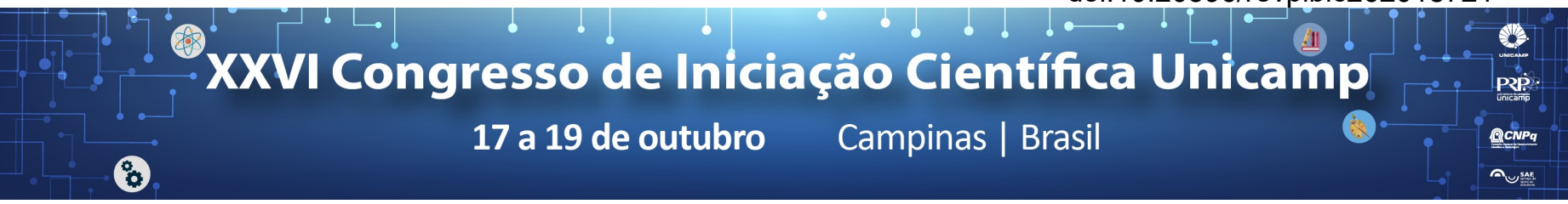

\title{
Análise Térmica Experimental de Concreto Estrutural reforçadas com PRFC (Polímeros Reforçados com Fibra de Carbono)
}

\section{Júlia P. Predebon*, Bruno Fernandes, Armando L. Moreno Júnior, Carla N. Costa.}

\section{Resumo}

Esta pesquisa é parte de um programa experimental à temperatura ambiente e a temperaturas elevadas, objetivando uma análise térmica em corpos de prova de concreto submetidos ao aquecimento acima dos $100{ }^{\circ} \mathrm{C}$, para avaliar os impactos do calor sobre estruturas de concreto reforçadas com PRFC (Polímeros Reforçados com Fibra de Carbono) instalados segundo a técnica NSM (Near Surface Mounted). Os resultados dão subsídios à avaliação do desempenho estrutural de vigas de concreto reforçado com PRFC em temperaturas típicas de incêndio, para o estudo de soluções que mantenham a segurança de estruturas de concreto de edifícios em situação de incêndio, após a reabilitação estrutural com reforços de PRFC.

\section{Palavras-chave:}

Concreto estrutural, altas temperaturas, PRFC (Polímeros Reforçados com Fibra de Carbono)

\section{Introdução}

Em altas temperaturas, os materiais estruturais têm as propriedades mecânicas reduzidas (COSTA, 2008). O uso de PRFC (Polímeros Reforçados com Fibra de Carbono) tem sido uma solução preferencial, opcional aos métodos usuais de reforço de estruturas de concreto no Brasil. Qual o desempenho de estruturas e concreto reforçadas com PRFC em uma situação de incêndio?

\section{Metodologia Empregada}

Em continuidade aos estudos de FERNANDES (2017), uma análise experimental foi conduzida envolvendo ensaios à temperatura ambiente e em altas temperaturas, sintetizados em cinco etapas (Figura 1).

Figura 1. Programa experimental.

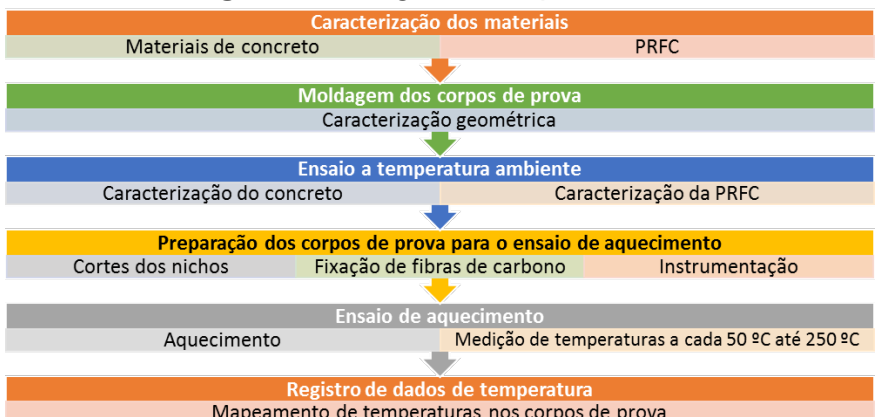

O processo de caracterização dos materiais para a produção dos corpos de prova, de sua a moldagem, e de preparação dos ensaios seguiram um controle de qualidade padronizado (Figura 2), conforme as normas da ABNT.

Figura 2. Equipamentos de ensaio e corpos de prova.

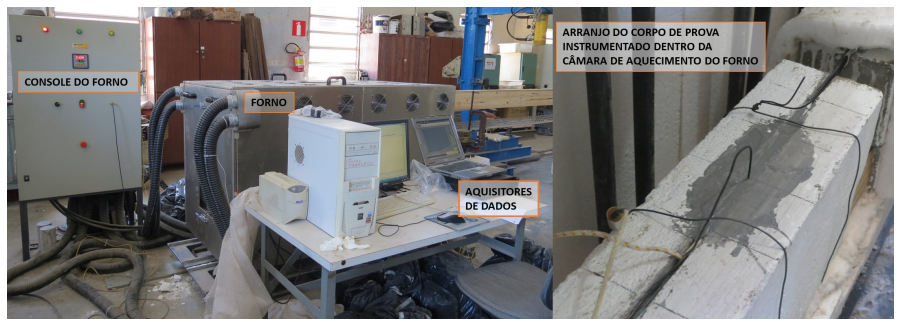

\section{Resultados e Discussão}

Os níveis de temperatura registrada nos "pontos de interesse", que são os nichos de alojamento das lâminas de PRFC segundo a técnica NSM (Near Surface Mounted), permitiu mapear os "pontos críticos" de localidade interna (Figura 3). Observourse que quando a superfície do corpo de prova atingiu $100^{\circ} \mathrm{C}$, nos nichos dos PRFC a temperatura atingiu níveis no intervalo $50^{\circ} \mathrm{C} \leq \boldsymbol{\theta} \leq 120^{\circ} \mathrm{C}$, que compreende a temperatura de transição vítrea, quando a resistência mecânica dos PRFC decresce drasticamente, perdendo a sua função estrutural.

Figura 3. Temperaturas aferidas.

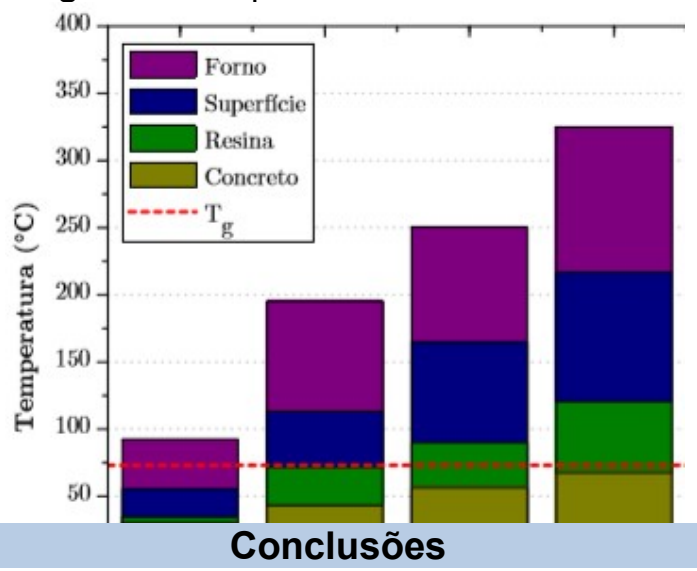

A ação térmica de incêndios impacta a segurança estrutural de obras de Engenharia Civil. Os resultados mostram que a localidade usual dos nichos de instalação dos PRFC segundo a técnica NSM (Near Surface Mounted) não assegura proteção térmica ao reforço, levando à falência estrutural do elemento de concreto sujeitos a temperaturas típicas de incêndios. Os resultados são preliminares, mas dão subsídios a estudos complementares para soluções de proteção térmica dos PRFC, e para critérios de projeto para as estruturas reabilitadas mantenham a segurança estrutural em situação de incêndio.

\section{Agradecimentos}

Ao PIBIC/CNPq e à FAEPEX (Proc. n 519.292/2016) pelo apoio à esta pesquisa.

FERNANDES, B. Efeito de elevadas temperaturas na aderência entre o concreto e laminado de polímero reforçado com fibra de carbono (PRFC) instalado segundo o método Near Surface Mounted (NSM). Relatório [s/n.]. Campinas: LES/FEC/UNICAMP, 2017. 75 p.

COSTA, C. N. Dimensionamento de elementos de concreto armado em situação de incêndio. 2008. 2 vol. Tese (Doutorado em Engenharia de Estruturas) Escola Politécnica, Universidade de São Paulo, São Paulo, 2008. 